\section{Halothane concentra- tions required to block the cardiovascular responses to incision (MAC CVR) in infants and children}

Yumiko Ishizawa MD, Shuji Dohi MD enfants et les nouveau-nés. Nous avons étudié 64 nouveau-nés et enfants, non prémédiqués, $A S A=1$. Chez chaque nouveauné ou enfant, l'anesthésie et été initiée lentement avec halothane et $\mathrm{N}_{2} \mathrm{O}$, suivie d'une intubation endotrachéale. Le MAC CVR a été évalué après qu'une concentration d'équilibre de fin d'expiration dhalothane soit établie depuis 10 minutes par la technique de Dixon. Les réponses positives correspondent à une augmentation de pression artérielle moyenne ou de fréquence cardiaque supérieure à $10 \%$. Le MAC CVR 50 de l'halothane avec $60 \%$ de $\mathrm{N}_{2} \mathrm{O}$ est de $1,16 \pm 0,23 \%$ de 1 à 6 mois; 1,17 $\pm 0,18 \%$ de 7 à 12 mois; $0,95 \pm 0,26 \%$ de 1 à 3 ans; et de $1,12 \pm 0,16 \%$ de $4 \grave{a} 7$ ans. La concentration nécessaire de 1 à 3 ans est moindre que dans les autres groupes d'âge ( $P$ $<0,05$ ). Les variations de pression artérielle moyenne ont été correlées avec les variations de fréquence cardiaque et de diamètre pupillaire. Ces résultats indiquent que les valeurs de MAC $C V R_{50}$ dhalothane chez les enfants et les nouveau-nés sont supérieures à celles requises pour bloquer la réponse motrice (MAC). Le besoin dhalothane pour bloquer les réponses cardiovasculaires est inférieures chez les enfants de 1 à 3 ans.

Age-related changes in autonomic activity in children under anaesthesia have not been well studied. Roizen $e t$ al.' suggested the concept of MAC BAR, the concentration required to block adrenergic responses to incision in 50\% of subjects. They assessed the depth of anaesthesia by measuring changes of plasma norepinephrine concentration. Although the MAC values for inhalational anaesthetic agents are higher in infants and children than in adults and they decrease in an age-related fashion, ${ }^{2-5}$ there are no reports of the anaesthetic concentration required to block the adrenergic responses to surgical stimulation in children. Therefore, we studied the anaesthetic concentration to block cardiovascular responses to skin incision (MAC CVR) in 64 infants and children aged between one month and seven years during halothanenitrous oxide $\left(\mathrm{N}_{2} \mathrm{O}\right)$ anaesthesia. 


\section{Methods}

This study was approved by our local review committee. Informed consent was obtained from parents or guardians of each patient.

Sixty-four unpremedicated patients, ASA physical status 1, were divided into four groups according to age: 1-6 months, 7-12 months, 1-3 years, and 4-7 years. Infants and children less than two years old received clear fluid $10 \mathrm{ml} \cdot \mathrm{kg}^{-1}$ four hours before anaesthesia, and those more than two years received the fluid six hours before anaesthesia. Surgery was performed at the inguinal region, lower abdomen, and extremities.

In the operating room, each infant or child was monitored using arterial blood pressure by oscillometric method with an appropriate cuff (DINAMAP(I), 1846SXP), ECG, oxygen saturation by pulse oximeter, and precordial stethoscope. General anaesthesia was induced with halothane, $\mathrm{N}_{2} \mathrm{O}$ and $\mathrm{O}_{2}$ by a mask using a T-piece circuit for children of body weight less than 15 $\mathrm{kg}$, and a small circle for those of more than $15 \mathrm{~kg}$, with a total fresh gas flow rate of $6 \mathrm{~L} \cdot \mathrm{min}^{-1}$. An intravenous catheter was placed for infusion of dextrose, $2 \%$, in Ringer's lactate solution at a rate of $6 \mathrm{ml} \cdot \mathrm{kg}^{-1} \cdot \mathrm{hr}^{-1}$. Then each patient's trachea was intubated without muscle relaxants. A steady state end-tidal halothane concentration was established and maintained for at least ten minutes before skin incision was instituted.

Mean arterial pressure (MAP) and heart rate (HR) were measured and recorded at four times: (I) in the ward with parents before the patient was brought to the operating room, (2) in the operating room before induction of anaesthesia, (3) at a steady state end-tidal halothane concentration before skin incision, and (4) during the two minutes following skin incision. In the last period the maximum of four consecutive MAP and HR measurements were selected as representative values. Pupillary diameter was also measured with a ruler at the latter two times. End-tidal gas was sampled through a 19G catheter, the tip of which was placed within $3 \mathrm{~cm}$ from the tracheal end of the endotracheal tube. ${ }^{6,7}$ End-tidal halothane concentrations were determined by the infrared absorption techniques (CAPNOMAC, Datax). Controlled ventilation was performed in each patient with a tidal volume of $8-10 \mathrm{ml} \cdot \mathrm{kg}^{-1}$ and a respiratory rate of $<30$ breaths $\cdot \mathrm{min}^{-1}$, to achieve adequate end-tidal volumes and times for sampling. ${ }^{8}$ End-tidal carbon dioxide tensions were maintained between 30 and $35 \mathrm{mmHg}$ during the study. On the day of the study, the gas analyzer was calibrated before the measurements started. At the end of the study the analyzer was recalibrated to determine whether any drift in linearity had occurred during the study. If there was a drift in the calibration after the study, the data was excluded from the present analysis.
Halothane concentration that blocked cardiovascular responses to skin incision in $50 \%$ of patients (MAC CVR50) was determined by the "up and down technique" of Dixon. ${ }^{9}$ An increase in MAP or HR of $10 \%$ or more from preincision value was considered a positive response. The first patient in each group was anaesthetized with an arbitrarily selected end-tidal halothane concentration. If the patient responded, then the end-tidal concentration was increased in the next patient. The amount of change in the halothane concentration (increase or decrease) was always $0.2 \%$. The first pair of patients with positive-negative responses to skin incision constituted the first two patients in that group and the patients studied before the first pair were not included in the analysis. In 52 of 64 patients, the halothane concentration which blocked the HR response was also determined. The first infant or child was included in the assessments of both MAP and HR response. In the subsequent measurements, if the child had a positive response of MAP but not of HR at $1.0 \%$ of halothane, we determined halothane concentration for the next child by the MAP response. Thus the end-tidal halothane concentration was increased to $1.2 \%$ for the next child. When we took $0.8 \%$ of halothane for the subject in the subsequent investigation of MAC CVR50 for MAP, the subject was also taken as the second one to determine MAC CVR50 for HR.

Patients were excluded who developed severe hypotension (MAP $<35 \mathrm{mmHg}$ in $1-6 \mathrm{mo}$, $<40 \mathrm{mmHg}$ in 6-12 mo, and $<45 \mathrm{mmHg}$ in children) and bradycardia ( $\mathrm{HR}<80$ beats $\cdot \mathrm{min}^{-1}$ in infants and $<70$ beats $\cdot \mathrm{min}^{-1}$ in children) at a given halothane concentration. Also patients with oxygen saturation $<95 \%$ with $\mathrm{FIO}_{2} 0.4$ were excluded.

The differences in MAC CVR50 among the four different age groups were analyzed using one-way analysis of variance followed by Neuman-Keuls test as a posthoc test. The relationships between changes in MAP and either changes in HR or those in pupillary diameter were analyzed by least squares regression analysis. $P<0.05$ was considered statistically significant.

\section{Results}

The four groups of infants and children studied were appropriate for age-predicted weight. There were no differences in rectal temperature or in end-tidal carbon dioxide tension during the study (Table I).

The MAP was decreased after induction of anaesthesia compared with MAP at the ward (Table I). There were no changes in HR in any group.

The positive-negative responses of MAP to skin incision occurred at different end-tidal halothane concentrations in the four age groups (Figure 1). The MAC 
TABLE I Characteristics of patients and results

\begin{tabular}{|c|c|c|c|c|c|c|c|c|c|c|c|}
\hline \multirow[b]{2}{*}{ Age } & \multirow[b]{2}{*}{$n$} & \multirow[b]{2}{*}{$\begin{array}{l}\text { Age } \\
(y r)\end{array}$} & \multirow[b]{2}{*}{$\begin{array}{l}\text { Weight } \\
(\mathrm{kg})\end{array}$} & \multirow[b]{2}{*}{$\begin{array}{l}\text { Rectal } \\
\operatorname{temp}\left({ }^{\circ} \mathrm{C}\right)\end{array}$} & \multirow[b]{2}{*}{$\begin{array}{l}\mathrm{PERCO}_{2} \\
(\mathrm{~mm} \mathrm{Hg})\end{array}$} & \multirow{2}{*}{$\begin{array}{l}100 \\
F I / F E \\
(\%)\end{array}$} & \multirow{2}{*}{$\begin{array}{l}M A C \\
C V R_{50} \\
(\%)\end{array}$} & \multicolumn{2}{|c|}{$M A P(m m H g)$} & \multicolumn{2}{|c|}{$H R$ (beats' $\min ^{-1}$ ) } \\
\hline & & & & & & & & At ward & $\begin{array}{l}\text { Pre- } \\
\text { incision§ }\end{array}$ & At ward & $\begin{array}{l}\text { Pre- } \\
\text { incision }\end{array}$ \\
\hline $1-6 \mathrm{mo}$ & 17 & $0.3 \pm 0.1$ & $6.4 \pm 1.5$ & $37.1 \pm 0.4$ & $29 \pm 5$ & $105 \pm 5$ & $1.16 \pm 0.23$ & $64 \pm 9$ & $47 \pm 8$ & $130 \pm 18$ & $133 \pm 13$ \\
\hline $7-12 \mathrm{mo}$ & 13 & $0.7 \pm 0.1$ & $8.4 \pm 1.3$ & $37.3 \pm 0.5$ & $31 \pm 6$ & $107 \pm 8$ & $1.17 \pm 0.18$ & $71 \pm 10$ & $52 \pm 9$ & $124 \pm 11$ & $125 \pm 13$ \\
\hline $1-3 y r$ & 21 & $2.2 \pm 0.8$ & $12.0 \pm 2.4$ & $37.4 \pm 0.4$ & $32 \pm 3$ & $106 \pm 8$ & $0.95 \pm 0.26^{*}$ & $76 \pm 10 \dagger$ & $54 \pm 7 \uparrow$ & $106 \pm 19 \dagger \ddagger$ & $109 \pm 14 \dagger$ \\
\hline 4-7 yr & 13 & $5.4 \pm 0.9$ & $18.1 \pm 3.7$ & $37.3 \pm 0.4$ & $32 \pm 5$ & $108 \pm 9$ & $1.12 \pm 0.13$ & $81 \pm 7 \dagger$ & $59 \pm 6 \dagger$ & $92 \pm 13 t t$ & $96 \pm 17 t t$ \\
\hline
\end{tabular}

Mean $\pm 1 \mathrm{SD}, \mathrm{FI}$ is inspired and FE is end-tidal halothane concentration.

${ }^{*} P<0.05$ compared with the other age groups (Neuman-Keuls test).

$\dagger P<0.05$ compared with $1-6$ months infants.

$\ddagger P<0.05$ compared with $6-12$ months infants.

§Pre-incision MAP is significantly lower than those at ward in all groups $(P<0.05)$.

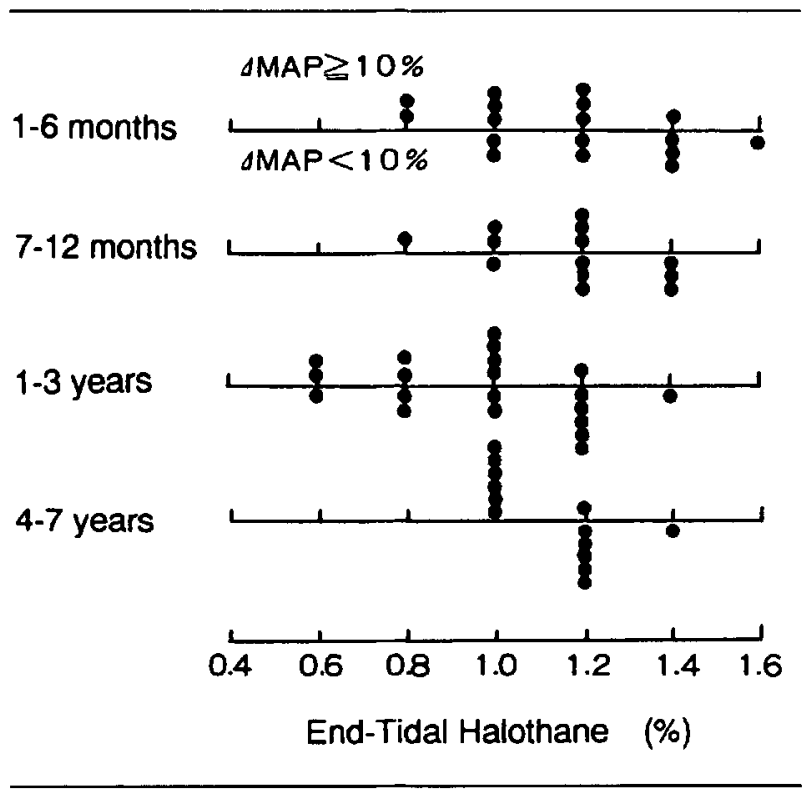

FIGURE 1 Data for individual patients are given as a filled circle. The circles above the horizontal line indicates the patient whose MAP increased more than $10 \%$ of pre-incision value to skin incision, and circles below that indicates MAP increased less than $10 \%$.

CVR50 of halothane for MAP with $60 \%$ of $\mathrm{N}_{2} \mathrm{O}$ were $1.16 \pm 0.23 \%$ in $1-6 \mathrm{mo}, 1.17 \pm 0.18 \%$ in $7-12 \mathrm{mo}$, $0.95 \pm 0.26 \%$ in $1-3 \mathrm{yr}$ and $1.12 \pm 0.13 \%$ in $4-7 \mathrm{yr}$. The MAC CVR50 in 1-3 yr was lower than in the other age groups $(P<0.05$, Table I). The increase in MAP to skin incision was correlated with the increase in HR in all groups (Figure 2), and correlated with the increase in pupillary diameter in the younger infants and children (Table II). The MAC CVR50 of halothane for HR responses was $1.15 \pm 0.18 \%$ for $1-6$ mo $(n=13), 1.20$ $\pm 0.14 \%$ for $7-12 \mathrm{mo}(n=12), 0.86 \pm 0.24 \%$ for $1-3$ $\mathrm{yr}(n=15)$ and $1.13 \pm 0.13 \%$ for $4-7 \mathrm{yr}(n=12)$. The values of MAC CVR50 for HR were not different from those for MAP responses in each age group. The

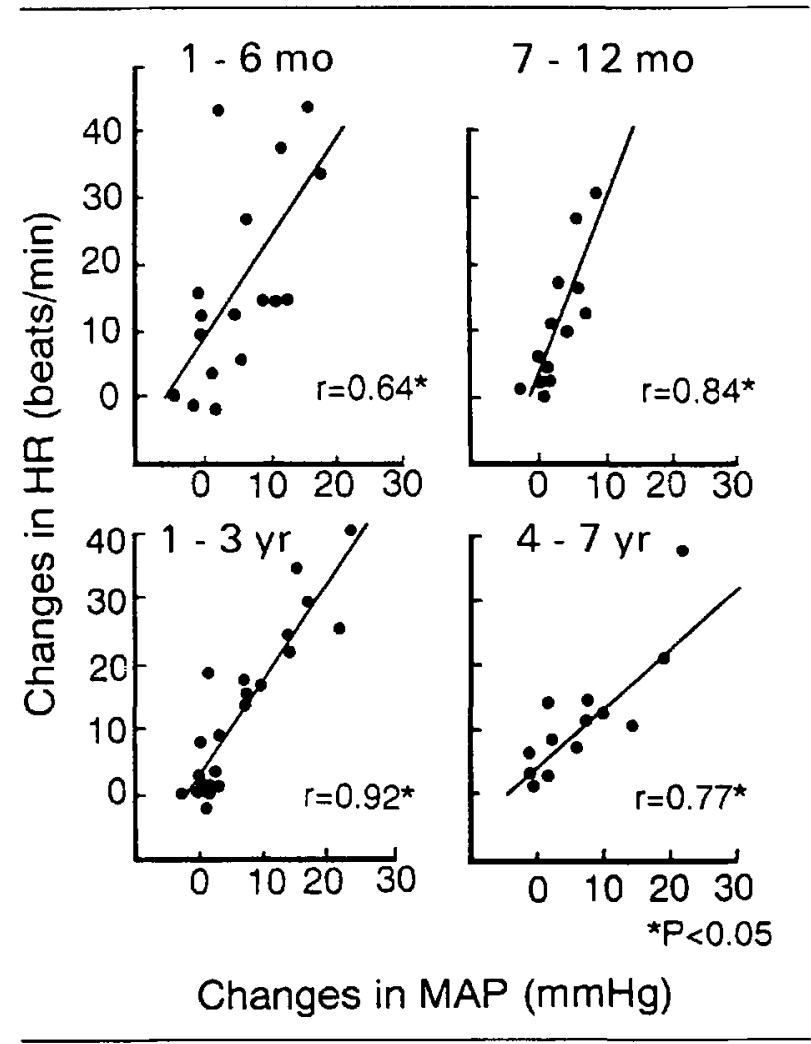

FIGURE 2 Relationship between changes in MAP and HR to skin incision. Each circle indicates individual change. Significant correlations were found in all age groups.

MAC CVR50 for HR in 1-3 yr children was lower than in the other age groups $(P<0.01)$.

Eight of 64 patients $(10.8 \%)$ developed arrhythmias during the induction of anaesthesia with inspired halothane concentration of $2.0-3.0 \%$. All were junctional rhythms and disappeared spontaneously within a few minutes. Five of the children were 4-7 yr, but there was no relationship between the incidence of arrhythmias and age. None of the patients developed severe bradycardia, 
TABLE II Changes in pupil diameter* in the patients with positive MAP response (responder) and those without (non-responder), and correlation coefficients of changes in pupil diameter and MAP.

\begin{tabular}{|c|c|c|c|c|c|}
\hline \multirow[b]{2}{*}{ Age } & \multicolumn{2}{|l|}{ Responder } & \multicolumn{2}{|c|}{ Non-responder } & \multirow{2}{*}{$\begin{array}{l}\text { Correlation } \\
\text { coefficients }\end{array}$} \\
\hline & Pre-incision & Incision & Pre-incision & Incision & \\
\hline $1-6 \mathrm{mo}$ & $1.4 \pm 0.4$ & $2.4 \pm 0.8 \uparrow$ & $1.6 \pm 0.2$ & $1.7 \pm 0.3$ & $0.81 \ddagger$ \\
\hline $7-12 \mathrm{mo}$ & $1.7 \pm 0.5$ & $2.8 \pm 0.9 \dagger$ & $1.4 \pm 0.2$ & $1.5 \pm 0.0$ & 0.58 \\
\hline $1-3 \mathrm{yr}$ & $1.8 \pm 0.3$ & $3.2 \pm 1.0 \dagger$ & $1.8 \pm 0.4$ & $2.0 \pm 0.6$ & $0.65 \ddagger$ \\
\hline $4-7 \mathrm{yr}$ & $1.4 \pm 0.2$ & $3.4 \pm 0.4 \dagger$ & $2.3 \pm 0.4$ & $2.7 \pm 0.6$ & $0.80 \ddagger$ \\
\hline
\end{tabular}

*Values are mean $\pm \mathrm{l} \mathrm{SD}$, and in $\mathrm{mm}$.

$\dagger P<0.01$ compared with pre-incision value.

$\ddagger P<0.05$.

but one showed severe hypotension (MAP $30 \mathrm{mmHg}$ ) during end-tidal halothane of $1.4 \%$. The patient was excluded from analysis.

\section{Discussion}

In infants and children the anaesthetic requirements for halothane in $60 \% \mathrm{~N}_{2} \mathrm{O}$ to block cardiovascular responses to incision (MAC CVR) were considerably higher than those required to block motor responses (MAC). The lowest value of MAC CVR and the smallest difference between MAC CVR and MAC in one to three year old children might suggest developmental changes in autonomic and cardiovascular activities. Responses in HR and in pupillary diameter following skin incision were correlated with the MAP responses in all groups of patients aged between one month and seven years.

Although neuroanatomical and functional requirements for pain perception are considered to be complete by birth in humans, ${ }^{10}$ autonomic regulation of cardiovascular function is not. ${ }^{11-14}$ Responses of heart rate and blood pressure to adrenergic stimuli develop in the postnatal period, but the developments of those responses are asynchronous. ${ }^{12-14}$ In infants and children, age-related changes in autonomic functions have not been investigated extensively. However, Finley et al. ${ }^{15}$ suggested that the sympathetic activity of the heart at five to ten years of age is relatively decreased. In our present study the MAC CVR50 of halothane was lowest in children of one to three years than in the other age groups. The reasons for age-related changes in MAC CVR50 of halothane are speculative. They may involve relatively decreased sympathetic activity, more depressive effects of halothane on the central sympathetic centres 16,17 as well as on release of catecholamines, ${ }^{18}$ and also decreased sensitivity of effector organs to adrenergic stimuli ${ }^{12,13}$ at that age.

In our study there was a difference between the value of MAC CVR50 and MAC. The values of MAC for $\mathrm{N}_{2} \mathrm{O}$ in infants and children are similar to those in adults. ${ }^{19,20}$ Anaesthetic depth of MAC CVR50 adding halothane and $60 \% \mathrm{~N}_{2} \mathrm{O}$ in each age group (1-6 mo to

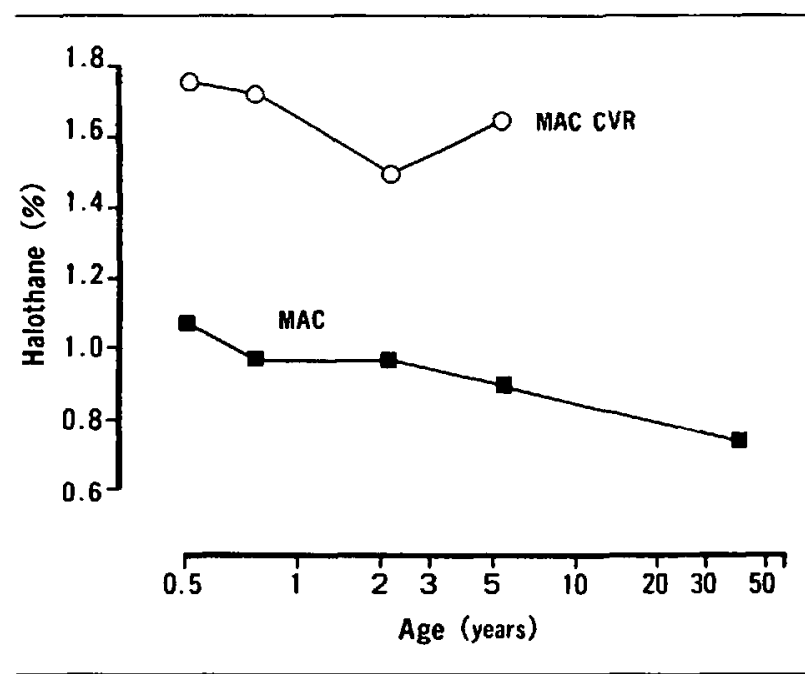

FIGURE 3 The values of MAC CVR50 are calculated as halothane concentrations. Age adjustments of MAC value for halothane were made based on available published data (Gregory et al. 1969).

4-7 yr) corresponds to $1.78,1.72,1.50$, and $1.64 \%$ of halothane concentration (Figure 3). Thus the difference between MAC CVR50 and MAC was smallest in children of one to three years.

We used $60 \% \mathrm{~N}_{2} \mathrm{O}$ in all patients during the measurements in order to determine MAC CVR 50 as clinically useful values. Although the cardiovascular advantage of adding $\mathrm{N}_{2} \mathrm{O}$ to halothane may not be as important in infants and children as in adults, ${ }^{21}$ maintenance of $\mathrm{HR}$ at preinduction values in our infants and children might be beneficial and may have resulted from the sympathetic effects of $\mathrm{N}_{2} \mathrm{O}$. Further clinical study is needed to determine whether the increase in sympathetic activity caused by $\mathrm{N}_{2} \mathrm{O}$ increases the anaesthetic requirement of halothane.

In small children, because of their greater cardiovascular susceptibility to volatile anaesthetics, ${ }^{21-23}$ there could be some controversy whether a deeper level of anaesthesia should be used to abolish the responses during their 
TABLE III Correlation coefficients between the decrease in MAP or $\mathrm{HR}$ with $1 \mathrm{MAC} C \mathrm{VR}$ of halothane and $\mathrm{N}_{2} \mathrm{O}$ and the increase in MAP or HR following skin incision

\begin{tabular}{lcc}
\hline & $M A P$ & $H R$ \\
\hline $1-6 \mathrm{mo}$ & 0.04 & $0.49^{*}$ \\
$7-12 \mathrm{mo}$ & 0.15 & 0.47 \\
$1-3 \mathrm{yr}$ & $-0.47^{*}$ & 0.09 \\
$4-7 \mathrm{yr}$ & -0.17 & -0.09 \\
\hline
\end{tabular}

$* P<0.05$.

surgery. Although the degree of decrease in MAP due to halothane and $\mathrm{N}_{2} \mathrm{O}$ anaesthesia at the level of MAC CVR50 was considerable, $26 \pm 9-28 \pm 13 \%$ of MAP, these decreases were comparable to the decrease in SAP with 1 MAC of halothane in neonates and infants reported by Lerman et al. ${ }^{4}$ Since greater decrease in MAP at given halothane concentration did not result in greater depression of MAP response to skin incision, direct cardiovascular depression is unlikely to cause an inability of the patients to respond to skin incision in these infants and children (Table III). However, in 1-3 yr children the more MAP decreased MAC CVR50, the less MAP increased following incision. Because there was no difference in the degree of decrease in MAP at MAC CVR50 among the four age groups, release of catecholamines by skin incision or the cardiac response to adrenergic stimuli might be depressed more with halothane in children of $1-3 \mathrm{yr}$.

Cardiovascular and neuroendocrine responses elicited by surgical stress may affect the incidence of postoperative complications in adults and neonates. ${ }^{24-26}$ In the present infants and children, although we determined MAC CVR50 using $>10 \%$ increase of MAP and HR as an all-or-none positive response, the anaesthetic requirement should also be reassessed with regards to postoperative outcome.

The present study indicates that when cardiovascular alterations were used to evaluate the patient's autonomic response to skin incision, infants and children need a substantially higher concentration of halothane than those required to block motor responses. Since cardiovascular depression by inhalational anaesthetics is considerable, it is important to know what degree of the autonomic responsiveness is acceptable in small children during anaesthesia.

\section{Acknowledgements}

The authors thank Dr. H. Naito, Professor and Chairman, Department of Anesthesiology, University of Tsukuba, for his valuable advice.

\section{References}

1 Roizen $M F$, Horrigan RW, Frazer BM. Anesthetic doses blocking adrenergic (stress) and cardiovascular responses to incision-MAC BAR. Anesthesiology 1981; 54: 390-8.

2 Gregory GA, Eger EI 2nd, Munson ES. The relationship between age and halothane requirement in man. Anesthesiology 1969; 30: 488-91.

3 Nicodemus HF, Nassiri-Rahimi C, Bachman L, Smith TC. Median effective doses $\left(E D_{50}\right)$ of halothane in adults and children. Anesthesiology 1969; 31: 344-8.

4 Lerman J, Robinson S, Willis MM, Gregory GA. Anesthetic requirements for halothane in young children 0-1 month and 1-6 months of age. Anesthesiology 1983; 59: 421-4.

5 Cameron $C B$, Robinson S, Gregory GA. The minimum anesthetic concentration of isoflurane in children. Anesth Analg 1984; 63: 418-20.

6 Rich GF, Sullivan MP, Adams JM. Is distal sampling of end-tidal $\mathrm{CO}_{2}$ necessary in small subjects? Anesthesiology 1990; 73: 265-8.

7 Badgwell JM, McLeod ME, Lerman J, Creighton RE. End-tidal $\mathrm{PCO}_{2}$ measurements sampled at the distal and proximal ends of the endotracheal tube in infants and children. Anesth Analg 1987; 66: 959-64.

8 Ozanne GM, Young WG, Mazzei WJ, Severinghaus $J W$. Multipatient anesthetic mass spectrometry: rapid analysis of data stored in long catheters. Anesthesiology 1981; 55: 62-70.

9 Dixon WJ. Quantal-response variable experimentation. The up-and-down method. I $n$ : McArthur JW (Ed.). Statistics in Endocrinology, Proceedings, Colton T. Cambridge, MIT Press, 1970, pp 251-67.

10 Anand KJS, Hickey PR. Pain and its effects in the human neonate and fetus. N Engl J Med 1987; 317: 1321-9.

11 Gootman PM, Gootman N, Buckley BJ. Maturation of central autonomic control of the circulation. Fed Proc 1983; 42: 1648-55.

12 Buckley NM, Gootman PM, Yellin EL, Brazeau P. Agerelated cardiovascular effects of catecholamines in anesthetized piglets. Circ Res 1979; 45: 282-92.

13 Boatman $D L$, Shaffer $R A$, Dixon $R L$, Brody $M J$. Function of vascular smooth muscle and its sympathetic innervation in the newborn dog. J Clin Invest 1965; 44 : 241-6.

14 Bartolome J, Mills E, Lau C, Slotkin TA. Maturation of sympathetic neurotransmission in the rat heart.V. Development of baroreceptor control of sympathetic tone. J Pharmacol Exp Ther 1980; 215: 596-600.

15 Finley JP, Nugent ST, Hellenbrand W. Heart-rate variability in children. Spectral analysis of developmental changes between 5 and 24 years. Can J Physiol Pharmacol 1987; 65: 2048-52. 
16 Millar RA, Warden JC, Cooperman LH, Price HL. Central sympathetic discharge and mean arterial pressure during halothane anaesthesia. Br J Anaesth 1969; 41: 918-28.

17 Bosnjak ZJ, Seagard JL, Wu A, Kampine JP. The effects of halothane on sympathetic ganglionic transmission. Anesthesiology 1982; 57: 473-9.

18 Lunn JJ, Rorie $D K$. Halothane-induced changes in the release and disposition of norepinephrine at adrenergic nerve endings in dog saphenous vein. Anesthesiology 1984; 61: 377-84.

19 Murray DJ, Mehta MP, Forbes RB, Dull DL. Additive contribution of nitrous oxide to halothane MAC in infants and children. Anesth Analg 1990; 71: 120-4.

20 Murray DJ, Mehta MP, Forbes RB. The additive contribution of nitrous oxide to isoflurane MAC in infants and children. Anesthesiology 1991; 75: 186-90.

21 Murray D, Vandewalker G, Matherne GP, Mahoney LT. Pulsed doppler and two-dimensional echocardiography: comparison of halothane and isoflurane on cardiac function in infants and small children. Anesthesiology 1987; 67: 211-7.

22 Barash PG, Glanz S, Katz JD, Taunt K, Talner NS. Ventricular function in children during halothane anesthesia: an echocardiographic evaluation. Anesthesiology 1978; 49: 79-85.

23 Wolf WJ, Neal MB, Peterson MD. The hemodynamic and cardiovascular effects of isoflurane and halothane anesthesia in children. Anesthesiology 1986; 64: 328-33.

24 Anand KJS, Sippell WG, Aynsley-Green A. Randomised trial of fentanyl anaesthesia in preterm babies undergoing surgery: effects on the stress response. Lancet 1987; 1: 62-6.

25 Anand KJS, Hickey PR. Halothane-morphine compared with high-dose sufentanil for anesthesia and postoperative analgesia in neonatal cardiac surgery. N Engl J Med 1992; 326: $1-9$.

26 Mangano DT. Perioperative cardiac morbidity. Anesthesiology 1990; 72: 153-84. 